\title{
Compreendendo a relação entre saúde do ambiente e saúde humana em comunidades Quilombolas de Santa Catarina
}

ZANK, S. ${ }^{\prime}$ ÁVILA, J.V.C. ${ }^{1 ;}$ HANAZAKI, N. ${ }^{1}$

Universidade Federal de Santa Catarina - UFSC. Programa de Pós-Graduação em Ecologia, Laboratório de Ecologia Humana e Etnobotânica, Campus Trindade s/n, 88040-900, Florianópolis/SC, Brasil. *Autor para correspondência: sofiazank@gmail.com

RESUMO: Neste artigo investigamos a relação entre a saúde humana e saúde do ambiente em comunidades quilombolas do litoral de Santa Catarina, analisando a situação de saúde destas comunidades, as percepções sobre elementos que influenciam a saúde humana, as plantas medicinais conhecidas e o mapeamento de ambientes que trazem benefícios para a saúde. Foi realizado entrevistas e listagem-livre de plantas medicinais com 184 adultos (63 no Morro do Fortunato, 56 na Santa Cruz e 65 na Aldeia), e uma reunião comunitária para a realização do mapeamento participativo em cada comunidade. As comunidades quilombolas percebem diversas influências na saúde, sendo que os elementos de cuidado com o corpo foram os mais citados. A qualidade da água/ar e recreação/lazer foram os benefícios mais reconhecidos das áreas florestais para a saúde humana. Foram identificadas 152 espécies de plantas medicinais, sendo que as espécies mais citadas são plantas cultivadas e/ou que ocorrem espontaneamente próximo às moradias. O mapeamento de serviços ambientais revela áreas prioritárias para a saúde, que estão localizadas em florestas e próximo aos corpos d'água, ressaltando a importância de conservar estes locais e de construir estratégias para garantir o acesso a eles pelas comunidades.

Palavras-chave: serviços ecossistêmicos, etnobotânica, plantas medicinais, saúde eco-cultural.

\begin{abstract}
The forest gives us health: relationships between environmental health and human health in Maroon communities of Santa Catarina. In this article we investigate the relationship between human health and environmental health in maroon communities of Santa Catarina, analyzing the health situation of these communities, the perceptions of elements that influence human health, medicinal plants known and mapping environments that bring health benefits. We conducted interviews and free-listing of medicinal plants with 184 adults (63 in Morro do Fortunato, 65 em Santa Cruz and 56 in Aldeia), and a community meeting for the realization of participatory mapping in each community. Maroon communities realize diverse influences on health, and the elements of care with the body were the most cited. The quality of the water/air and recreation/leisure were the most recognized benefits of forests to human health. 152 species of medicinal plants have been identified, and the most cited species are cultivated plants and/or occurring spontaneously near the houses. The mapping of environmental services reveals priority areas for health, which are located in forests and near the water bodies, emphasizing the importance of conserving these places and build strategies to ensure access to them by communities.
\end{abstract}

Keywords: ecosystem services, ethnobotany, medicinal plants, eco-cultural health.

\section{INTRODUÇÃO}

Os ecossistemas naturais fornecem bens e serviços que são importantes para a saúde e bem-estar das populações humanas (MEA, 2005). A relação de interdependência entre a saúde humana e a do ambiente é incorporada pela abordagem da saúde eco-cultural, que considera conjuntamente a saúde ou patologia dos ecossistemas e as suas implicações para o modo de vida, saúde e bem-estar humano (Rapport \& Maffi, 2011). Essa abordagem considera também a relação entre 
serviços ecossistêmicos e modo de vida tradicional de populações humanas (Rapport \& Maffi, 2011), sendo que os serviços podem ser oriundos tanto de ecossistemas naturais, como de ambientes manejados como campos e áreas agrícolas.

Serviços ecossistêmicos são os benefícios que as pessoas obtêm dos ecossistemas e compreendem serviços de provisão (como alimentos, água potável, recursos medicinais), de regulação (como proteção contra inundações), de suporte (como o ciclo dos nutrientes), e culturais (como patrimônio cultural, recreação) (MEA, 2005). As plantas medicinais são serviços de provisão que desempenham um papel central na medicina tradicional.

Os quilombolas, comunidades tradicionais que descendem de escravos negros, possuem identidade intimamente relacionada a terra, já que é a partir dela que constituem suas relações sociais, econômicas, culturais e são transmitidos bens materiais e imateriais (SEPPIR, 2013). Sua visibilidade social é recente, fruto da luta pela terra, da qual, em geral, não possuem escritura (Diegues et al.,1999). Estas comunidades costumam ser formadas por forte vínculo de parentesco e podem estar em situação de vulnerabilidade social, o que afeta diretamente a saúde da população (Freitas et al., 2011).

O crescimento da urbanização fez com que muitas comunidades quilombolas, que antes encontravam-se relativamente isoladas em meio a ecossistemas naturais e rurais, passassem a estar inseridas próximas aos centros urbanos, causando modificação nos seus modos de vida e no uso da terra. Assim, é importante compreender quais são os ambientes mais importantes para a manutenção da saúde quilombola, de forma a criar estratégias para conservar estes locais e as práticas tradicionais que os mantêm.

Estudos etnobotânicos podem contribuir para entendimento das relações entre saúde ecossistêmica e saúde humana, já que estes estudos investigam os conhecimentos, práticas e percepções das próprias comunidades em relação ao processo de saúde (Zank et al., 2015). O método de mapeamento participativo pode ser uma ferramenta poderosa para identificar áreas importantes para a gestão da saúde ambiental e humana.

O objetivo desta pesquisa foi investigar a relação entre a saúde humana e saúde do ambiente em três comunidades quilombolas de Santa Catarina. Para isso, analisamos as compreensões locais sobre saúde e doença, a percepção sobre elementos que influenciam a saúde humana e o conhecimento tradicional sobre plantas medicinais, que é um recurso importante para a manutenção da saúde. Para colaborar nas discussões sobre a importância do território tradicional para a saúde e bem-estar destas populações, foi mapeado os benefícios ecossistêmicos que colaboram para a saúde das comunidades quilombolas.

\section{MATERIAIS E MÉTODOS Área de Estudo}

As três comunidades quilombolas estão localizadas no litoral centro Sul de Santa Catarina, nos municípios de Garopaba (comunidades Morro do Fortunato e Aldeia) e Paulo Lopes (comunidade Santa Cruz), dentro do domínio Mata Atlântica. A vegetação varia desde áreas de Floresta Ombrófila Densa a áreas de restinga em solo arenoso. Morro do Fortunato foi reconhecida como território Quilombola em 2006, Aldeia em 2010 e Santa Cruz em 2007 (Fundação Cultural Palmares, 2014). Mesmo com este reconhecimento, ainda é necessária a delimitação oficial de seus territórios.

As três comunidades encontram-se em situações diferentes de urbanização. Morro do

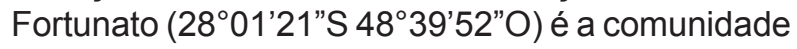
mais rural, distante cerca de $7 \mathrm{~km}$ do centro de Garopaba, está localizada na encosta de um morro e é cercada por vegetação nativa. Aldeia ( $28^{\circ} 06^{\prime} 23^{\prime \prime} S$ $48^{\circ} 40^{\prime} 43^{\prime \prime O}$ ) é a mais urbanizada,, inserida na malha urbana e cortada pela rodovia de acesso ao centro de Garopaba. A comunidade de Santa Cruz $\left(27^{\circ} 58^{\prime} 24^{\prime \prime} S 48^{\circ} 41^{\prime} 16^{\prime \prime}\right.$ ), localizada ao longo de uma estrada não asfaltada próximo ao centro de Paulo Lopes, está em uma situação intermediária de urbanização em relação às outras duas.

Características gerais das três comunidades são descritas por Ávila et al. (2015). As comunidades são pequenas, com 30 a 35 residências e 90 a 130 habitantes. Morro do Fortunato é a comunidade com maior quantidade de vegetação nativa no seu território, devido ao aumento da vegetação nas últimas décadas decorrente da diminuição da prática da agricultura e a busca por trabalhos assalariados; já na Aldeia e na comunidade de Santa Cruz houve a diminuição da vegetação nativa em decorrência da urbanização e pelo desmatamento (Ávila et al., 2015). Mesmo assim, o Morro do Fortunato é onde existe a maior porcentagem de pessoas que obtém renda através da agricultura.

O Catolicismo é a principal religião nas três comunidades, seguida das religiões Evangélicas; na Santa Cruz algumas pessoas são da religião de Matriz Africana Umbanda. Nas três comunidades existe a manutenção de práticas tradicionais de saúde, como o uso de plantas medicinais e a existência de benzedeiras. 


\section{Métodos}

Esta pesquisa foi aprovada pelo Comitê de Ética em Pesquisa com seres Humanos da Universidade Federal de Santa Catarina (18847013.0.0000.0121 de 14/08/2013) e teve acesso ao conhecimento tradicional autorizado pelo IPHAN (01450.012607/2013-20). A participação dos informantes foi condicional às suas anuências prévias.

Foi realizado um censo entre os moradores adultos, maiores de 18 anos, que estavam dispostos a participar da pesquisa, descrito em Ávila et al. (2015). Foram entrevistados 184 adultos (representatividade de $80 \%$ do total de adultos), sendo 63 no Fortunato (representatividade de 90\%), 56 na Santa Cruz (representatividade de $70 \%$ ) e 65 na Aldeia (representatividade de $80 \%$ ). Individualmente, perguntamos sobre o uso de medicamentos industrializados ("Você utiliza medicamentos industrializados? Para o tratamento de quais doenças?") e sobre elementos que influenciam a saúde humana ("O que nos ajuda a ter saúde?" e "As matas/florestas ajudam na nossa saúde? Como?"), e foi realizada lista livre das plantas medicinais conhecidas, anotando também informações sobre o uso e locais de obtenção.

As plantas citadas foram coletadas ou fotografadas para a identificação botânica. As amostras coletadas foram herborizadas seguindo procedimentos sugeridos por Cunningham (2001), e foram identificados através de bibliografia (Lorenzi, 2000; Lorenzi \& Matos, 2008) e consulta a especialistas. Foi utilizado o sistema de classificação APG III e os nomes foram conferidos de acordo com a base de dados da Flora do Brasil (Lista de Espécies da Flora do Brasil, 2015) e do Missouri Botanical Garden (MOBOT, 2015). Espécimes testemunho foram enviados para depósito no herbário FLOR da UFSC, e no Herbário do Instituto Federal de Educação, Ciência e Tecnologia do Amazonas - EAFM- (número de coleta de 1 a 482).

A classificação das indicações terapêuticas dos medicamentos industrializados foi realizada de acordo com a Classificação Internacional de doenças (CID 10) da Organização Mundial de Saúde (WHO, 2014).

Em uma reunião comunitária foram realizados mapeamentos participativos (De Boef \& Thijssen, 2007) para identificar o reconhecimento dos ambientes e dos seus benefícios percebidos à saúde humana pelos moradores. Estas reuniões ocorreram na sede das associações em Morro do Fortunato e Aldeia, e na casa de uma das moradoras na Santa Cruz, já que não existe um espaço comunitário nesta comunidade. Nesta reunião estavam presentes 12 pessoas no Fortunato, 14 na Santa Cruz e 20 na Aldeia. Os moradores foram estimulados a mapear ambientes que colaboram com os serviços ecossistêmicos de manutenção do clima, obtenção de recursos medicinais, obtenção de alimentos, serviços culturais (educação, locais históricos, recreação/lazer, ecoturismo, locais com importância espiritual) e desserviços (locais barulhentos, locais perigosos, locais que trazem risco a saúde).

O mapeamento esquemático produzido na reunião foi posteriormente adaptado para imagens de satélite e as localizações dos benefícios foram sobrepostas, gerando um mapa com áreas com diferentes intensidades de importância, escalonadas de 0 (sem benefício) a 5 (maior número de benefícios identificados). Os limites das comunidades foram definidos de acordo com Ávila (2015).

Usamos análise de conteúdo (Bernard \& Ryan, 2010) para sistematizar os elementos de influência na saúde humana, codificando e agrupando as respostas de acordo com os temas e os padrões identificados. Foi utilizado o método de rarefação para comparar a riqueza de plantas conhecidas nas três comunidades (Gotelli, 2008), sendo que a análise foi realizada no programa EstimateS 8.0 (Colwell, 2007).

\section{RESULTADOS}

Nas três comunidades estudadas existe 0 acesso facilitado ao sistema formal de saúde. Os centros de saúde estão distantes a cerca de $1 \mathrm{~km}$ das comunidades. Em cada uma das comunidades há uma agente de saúde para atender e orientar as famílias e há atendimento médico pelo menos uma vez ao mês nas próprias comunidades.

$\mathrm{Na}$ Aldeia existe maior porcentagem de pessoas que utilizam medicamentos industrializados (70\%) quando comparado com Morro do Fortunato e Santa Cruz (52\%). Estes recursos são utilizados para tratar principalmente doenças como pressão alta, problemas no coração, dores na coluna, diabetes mellitus, colesterol, dores de cabeça/ enxaqueca (Tabela 1). No Morro do Fortunato existe maior porcentagem de pessoas que utilizam medicamentos para problemas de pressão alta e de diabetes mellitus, quando comparado com as outras duas comunidades. Em Santa Cruz se destaca o uso de medicamentos para tratar dores de cabeça/ enxaqueca e para problemas de anemia.

Quando questionados "O que nos ajuda a ter saúde?", a maioria dos entrevistados, para as três comunidades, relatou elementos relacionados ao cuidado com o corpo, como a alimentação, fazer exercícios físicos e não usar drogas (Figura 1). Elementos relacionados ao cuidado com a mente (p.ex. tranquilidade, não se preocupar) foram mais citados para a comunidade da Aldeia, enquanto,

Rev. Bras. PI. Med., Campinas, v.18, n.1, p.157-167, 2016. 
TABELA 1. Categorias de doenças tratadas por medicamentos industrializados nas comunidades quilombolas do Morro do Fortunato ( $n=63$ entrevistas), Santa Cruz ( $n=56$ entrevistas) e Aldeia ( $n=65$ entrevistas), litoral de Santa Catarina.

\begin{tabular}{|c|c|c|c|c|}
\hline & $\begin{array}{c}\text { Morro do } \\
\text { Fortunato } \\
(\%)\end{array}$ & $\begin{array}{c}\text { Santa } \\
\text { Cruz } \\
(\%)\end{array}$ & $\begin{array}{l}\text { Aldeia } \\
(\%)\end{array}$ & $\begin{array}{c}\text { Total } \\
\text { geral } \\
(\%) \\
\end{array}$ \\
\hline Sistema circulatório (pressão alta, coração) & 37 & 32 & 41 & 37 \\
\hline Sistema osteomuscular (dor na coluna, joelho, etc) & 8 & 7 & 17 & 11 \\
\hline $\begin{array}{l}\text { Doenças das glândulas endócrinas e da nutrição (diabetes mellitus, } \\
\text { colesterol) }\end{array}$ & 14 & 5 & 9 & 10 \\
\hline Sistema Nervoso (dor de cabeça, enxaqueca) & 3 & 13 & 6 & 7 \\
\hline Afecções ou dores não definidas (dor, infecções, etc) & 5 & 5 & 6 & 5 \\
\hline Sistema genitário Feminino (cólica, menopausa, anticoncepcional) & 5 & 4 & 6 & 5 \\
\hline Sistema Digestório (dor no estômago) & 5 & 5 & 3 & 5 \\
\hline Sistema Respiratório (gripe, bronquite) & 2 & 2 & 9 & 5 \\
\hline Doenças Mentais e comportamentais (ansiedade, depressão) & 2 & 0 & 6 & 3 \\
\hline Doenças do Sangue (anemia) & 0 & 5 & 2 & 3 \\
\hline Sistema Urinário (rins) & 0 & 0 & 6 & 2 \\
\hline Sistema Sensorial (labirintite, olhos) & 0 & 0 & 5 & 2 \\
\hline Lesões, envenenamento e outras doenças de causas externas (alergia) & 0 & 2 & 0 & 1 \\
\hline Sistema genitário masculino (hormônio masculino) & 0 & 0 & 2 & 1 \\
\hline
\end{tabular}

a medicina formal (atendimento médico, uso de medicamentos industrializados) foi mais citada para a comunidade de Santa Cruz (Figura 1). Elementos do ambiente (p.ex. uso de plantas medicinais, local sem lixo e esgoto) e de espiritualidade (fé, Deus, Jesus) foram menos lembrados (Figura 1).

A influência das áreas de floresta na saúde humana foi percebida em benefícios como a qualidade da água e do ar (p.ex. "Onde tem mais planta, ar é mais puro"), seguida de recreação e bem-estar ("O ambiente natural traz equilíbrio pra mente e pro corpo", "Mata é bom, traz tranquilidade") e das condições climáticas ("Se desmatar fica mais quente. A mata ajuda a deixar o ar mais fresco") (Figura 2). As áreas florestais, como fonte de recursos medicinais ("A mata é onde tem remédio, e tem que saber como usar") e na qualidade de recursos alimentares ("É onde tem ervas e alimentos mais naturais que os comprados") foram citados por menos de $10 \%$ dos entrevistados (Figura 2).

Foram identificadas 152 espécies de plantas medicinais que foram citadas como conhecidas pelos moradores, sendo que a riqueza registrada na comunidade Aldeia (128 espécies) diferiu significativamente, da Santa Cruz (85 espécies) e Morro do Fortunato (78 espécies) (Figura 3). As espécies mais citadas (citação superior a $20 \%$ nas três comunidades) são plantas cultivadas e/ou que ocorrem espontaneamente próximo às moradias (Tabela 2), e entre elas destacam-se também plantas usadas ritualisticamente contra "mau olhado", para banhos de limpeza e em defumadores, como alecrim (Rosmarinus officinalis L.) e a arruda (Ruta graveolens L.).

As plantas medicinais são obtidas principalmente através do cultivo e, em proporções menores, através da extração em ambientes naturais e da compra (Figura 4). O quintal próprio e os quintais dos vizinhos são os principais locais de obtenção para as plantas cultivadas. As plantas extraídas são obtidas em áreas de mata, campo e banhados (Figura 5) e a compra de plantas medicinais é realizada em mercados e feiras, farmácias e comércios locais.

Diferentes serviços ecossistêmicos são percebidos a partir dos ecossistemas naturais e manejados. A comunidade do Morro do Fortunato reconhece mais áreas que auxiliam na manutenção do clima (Tabela 3) e, similar à Aldeia, reconhece áreas para obtenção de alimento e de serviços culturais. Os desserviços registrados foram principalmente na Santa Cruz, por esgoto, lixo e poluição industrial, e na Aldeia pelo barulho e perigo de atropelamento na rodovia.

O mapeamento dos benefícios ambientais para a saúde humana revelou locais com diferentes intensidades de importância. No Morro do Fortunato e Aldeia existem áreas com maior intensidade de importância, enquanto, que na Santa Cruz foram identificadas poucas áreas que trazem benefícios

Rev. Bras. PI. Med., Campinas, v.18, n.1, p.157-167, 2016. 


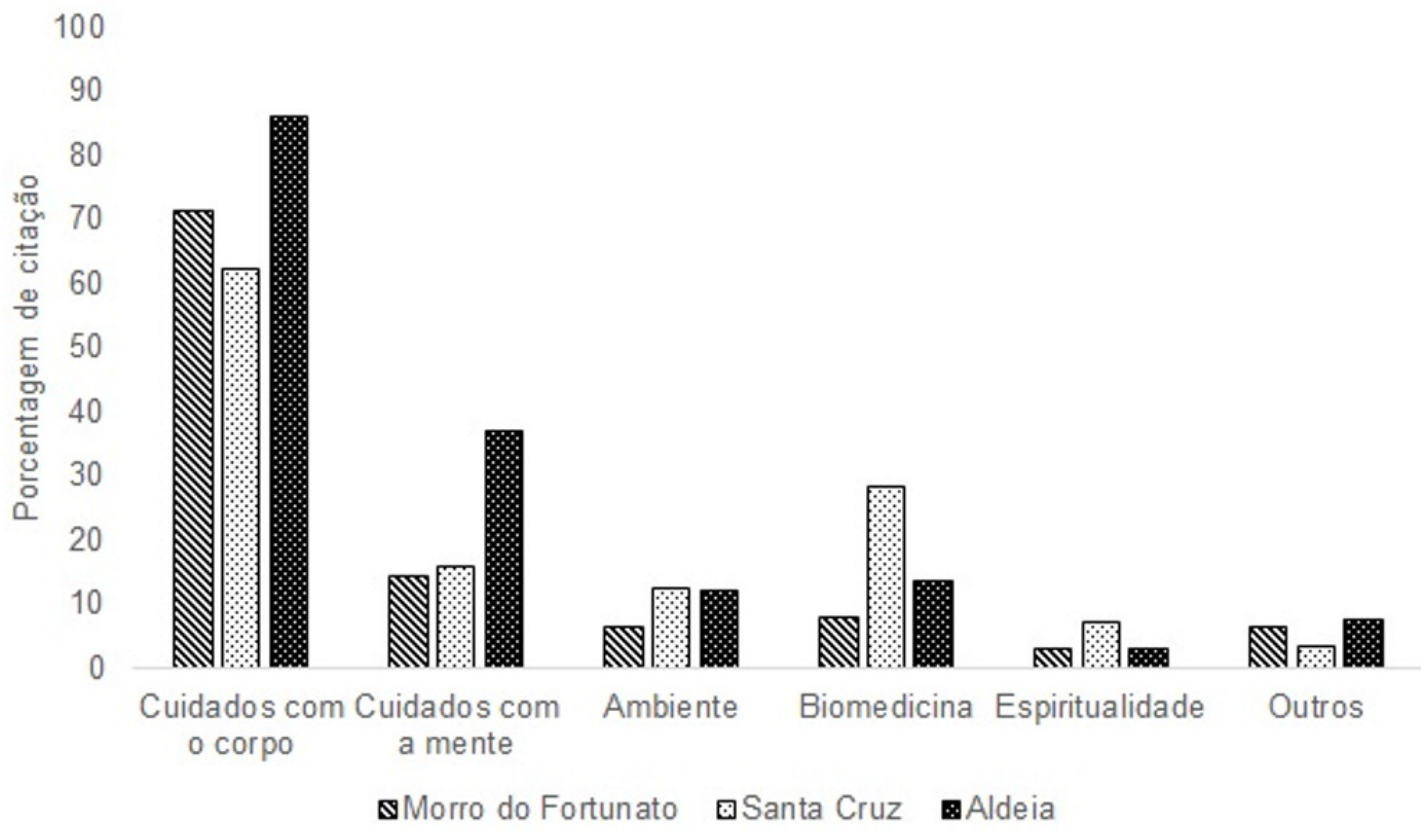

FIGURA 1. Percepção de elementos que influenciam a saúde humana nas comunidades quilombolas do Morro do Fortunato ( $n=63$ entrevistas), Santa Cruz ( $n=56$ entrevistas) e Aldeia ( $n=65$ entrevistas).

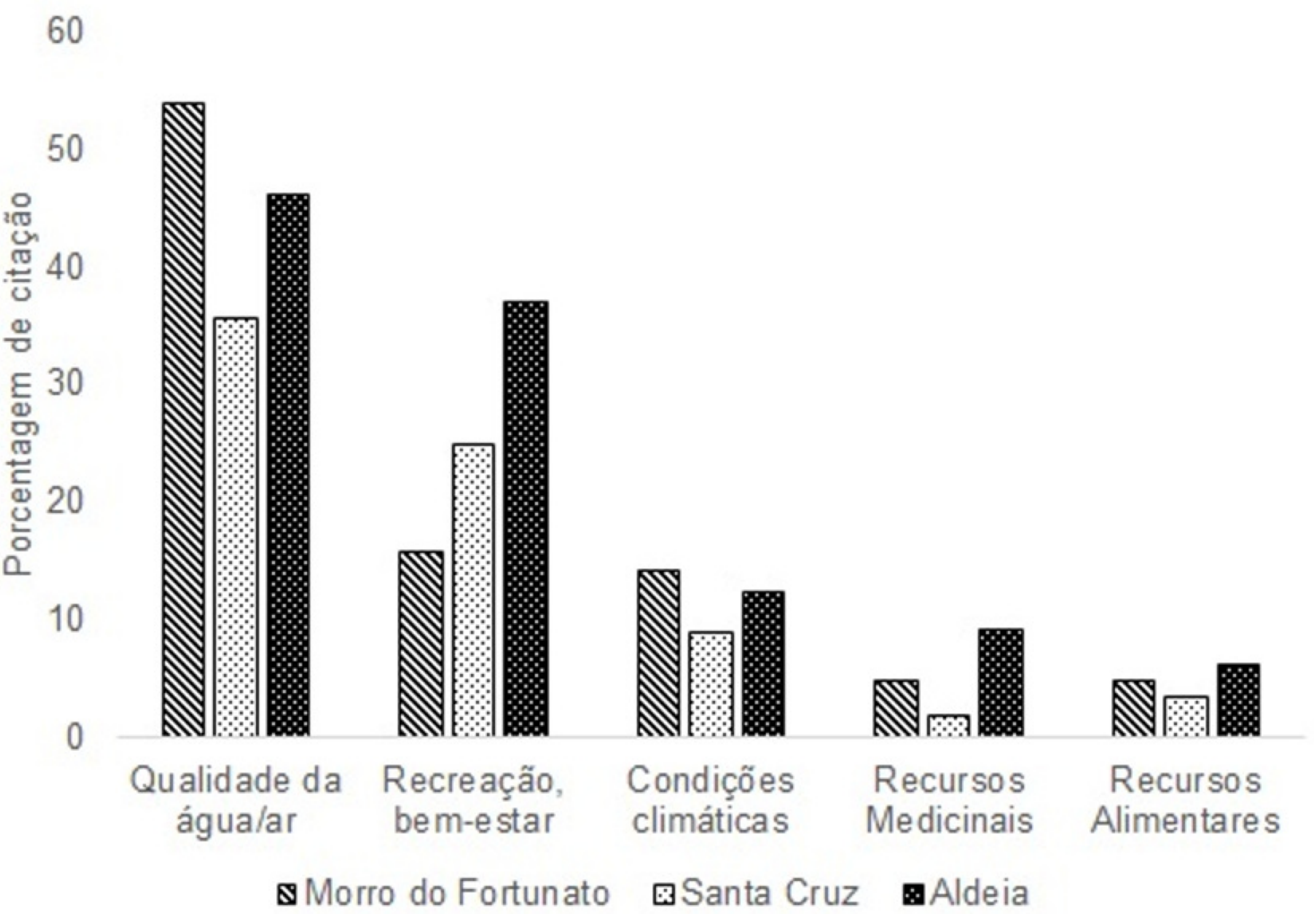

FIGURA 2. Percepção dos benefícios das áreas florestais para a saúde humana para as comunidades quilombolas do Morro do Fortunato $(n=63)$, Santa Cruz $(n=56)$ e Aldeia $(n=65)$.

ambientais. Nas três comunidades as áreas mais importantes estão próximas às áreas de água fresca, que correspondem ao entorno dos rios no Morro do Fortunato e Santa Cruz, e lagoa da Encantada e nascentes na Aldeia. As áreas reconhecidas como benéficas para a saúde englobam o mosaico de ecossistemas, incorporando tanto às áreas florestais, como também às áreas manejadas agricultura e campo (Figura 6). Além disso, as áreas importantes para o Morro do Fortunato encontramse dentro do seu território, porém na Santa Cruz e na Aldeia muitas áreas importantes encontram-se fora do que a comunidade relata como seu território atualmente. 


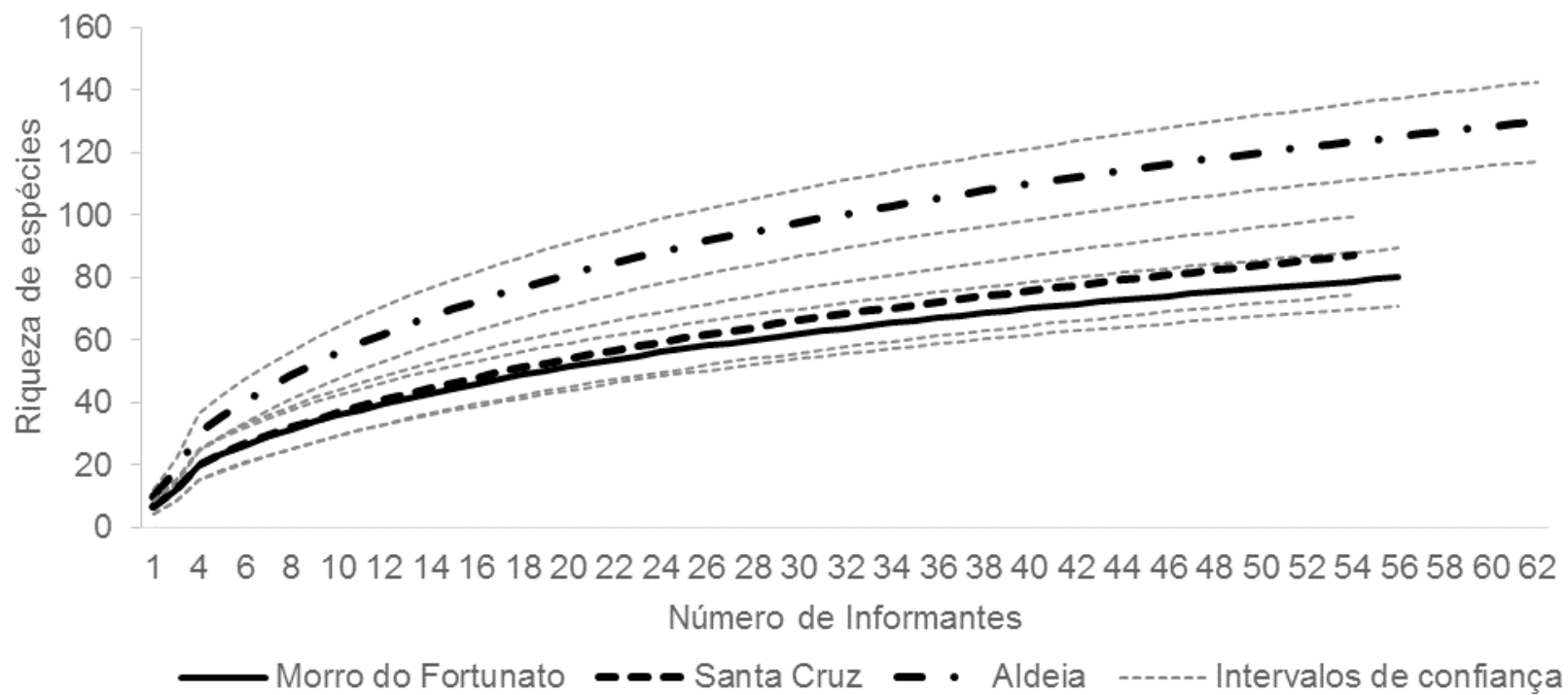

FIGURA 3. Riqueza esperada (curva de rarefação) comparando a riqueza de plantas medicinais citadas nas comunidades quilombolas do Morro do Fortunato ( $n=57$ entrevistas), Santa Cruz ( $n=54$ entrevistas), Aldeia ( $n=64$ entrevistas). Intervalo de confiança em 95\% para $n=54$ : Morro do Fortunato $88>$ Cl95\% > 79; Santa Cruz 87 > Cl95\% > 100; e Aldeia 124 > Cl95\% > 136).

TABELA 2. Plantas medicinais com citação superior a $20 \%$ nas comunidades quilombolas do Morro do Fortunato( $n=57$ entrevistas), Santa Cruz ( $n=54$ entrevistas) e Aldeia ( $n=64$ entrevistas).

\begin{tabular}{|c|c|c|c|c|c|}
\hline Nome local & Identificação botânica & Aldeia & Fortunato & $\begin{array}{c}\text { Santa } \\
\text { Cruz }\end{array}$ & Total \\
\hline Erva-cidreira & Melissa officinalis L. & $33 \%$ & $56 \%$ & $56 \%$ & $55 \%$ \\
\hline Hortelã & Mentha spp. & $75 \%$ & $23 \%$ & $35 \%$ & $53 \%$ \\
\hline Cana/capim cidreira/limão & Cymbopogoncitratus(DC.) Stapf & $42 \%$ & $53 \%$ & $37 \%$ & $51 \%$ \\
\hline Laranja & Citrus sinensis (L.) Osbeck & $42 \%$ & $32 \%$ & $43 \%$ & $45 \%$ \\
\hline Alecrim & Rosmarinus officinalis $\mathrm{L}$. & $33 \%$ & $39 \%$ & $33 \%$ & $40 \%$ \\
\hline Macela galega & Cotula australis (Siebere $x$ Spreng.) Hook. f. & $31 \%$ & $26 \%$ & $19 \%$ & $30 \%$ \\
\hline Boldo, boldo folha larga & Plectranthus barbatus Andr. & $34 \%$ & $12 \%$ & $28 \%$ & $29 \%$ \\
\hline Arruda & Ruta graveolens L. & $20 \%$ & $21 \%$ & $30 \%$ & $27 \%$ \\
\hline Limão & Citrus spp. & $25 \%$ & $16 \%$ & $20 \%$ & $24 \%$ \\
\hline Loro & Laurus nobilis L. & $25 \%$ & $26 \%$ & $9 \%$ & $24 \%$ \\
\hline Erva doce & Pimpinella anisum $\mathrm{L}$. & $19 \%$ & $11 \%$ & $28 \%$ & $22 \%$ \\
\hline Camomila, maçanilha & Matricaria recutita L. & $30 \%$ & $9 \%$ & $17 \%$ & $22 \%$ \\
\hline Malva & Malva parviflora L. & $18 \%$ & $25 \%$ & $13 \%$ & $22 \%$ \\
\hline
\end{tabular}

\section{DISCUSSÃO}

Atualmente mais da metade dos entrevistados nas três comunidades quilombolas utilizam algum tipo de medicamento industrializado para o tratamento de doenças, demonstrando a importância do sistema formal de saúde nestas comunidades. A hipertensão arterial é a doença com maior porcentagem de citação de uso de medicamentos industrializados. A hipertensão destaca-se no contexto das doenças mais importantes por razões étnicas nas populações afrodescendentes (Brasil, 2001). No entanto, segundo Agyemang et al. (2009), a pressão arterial está mais relacionada ao estilo de vida - reflexo da situação socioeconômica - do que por diferenças genéticas. As dores na coluna têm relação, segundo os entrevistados, aos trabalhos desenvolvidos que exigem esforço físico, como o trabalho como empregadas domésticas, exercido por muitas mulheres quilombolas, e os trabalhos na construção civil exercidos pelos homens. A diabetes mellitus, aparentemente com alta prevalência, e a anemia falciforme, também são doenças frequentes nas populações de afrodescendentes (Brasil, 2001). 


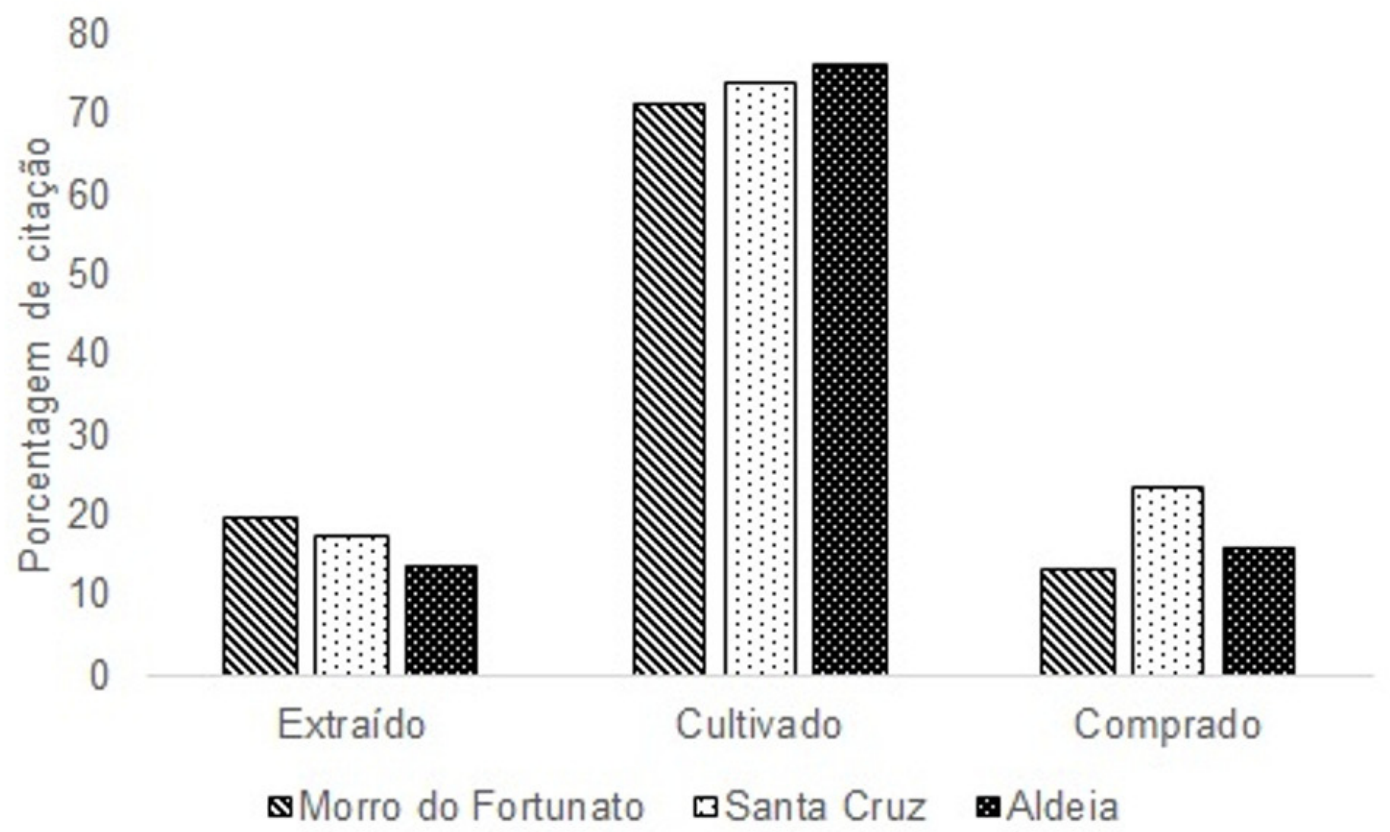

FIGURA 4. Forma de obtenção das plantas medicinais nas comunidades quilombolas do Morro do Fortunato ( $n=387$ citações), Santa Cruz ( $n=368$ citações) e Aldeia ( $n=644$ citações).

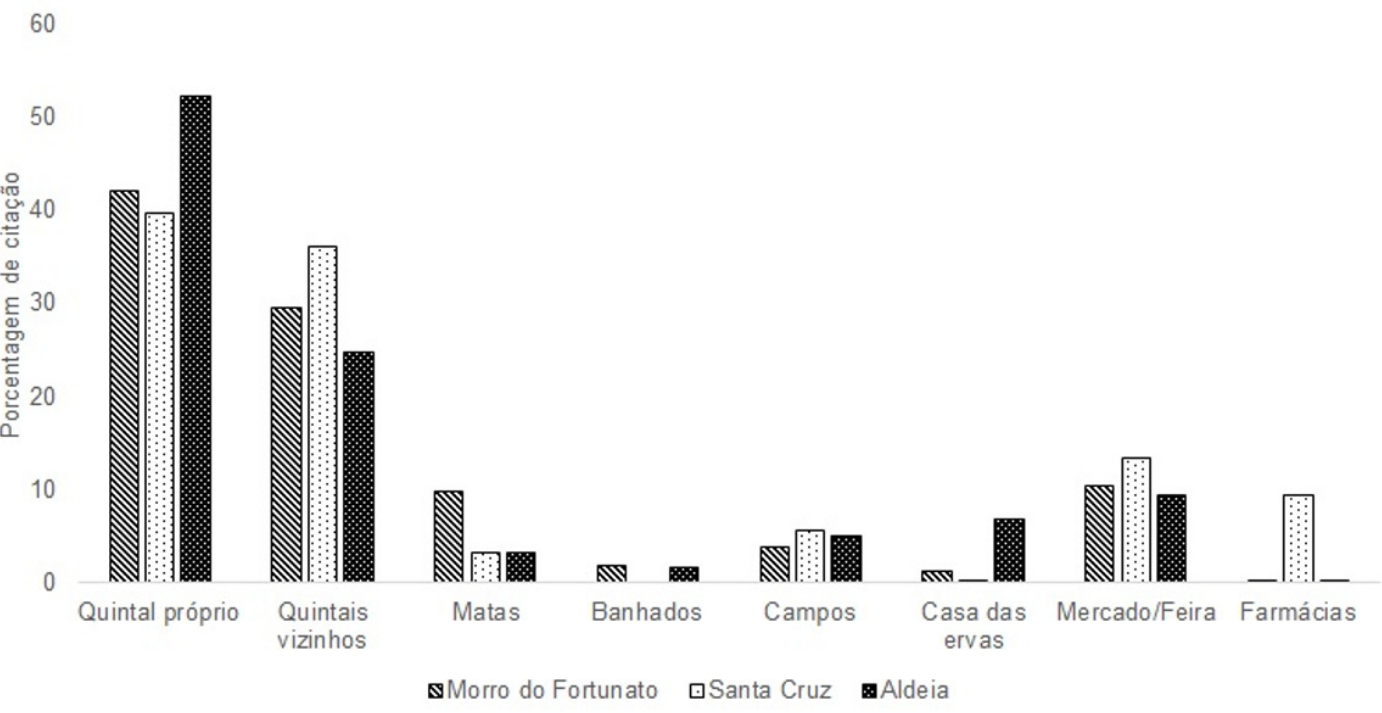

FIGURA 5. Locais de obtenção de plantas medicinais nas comunidades quilombolas do Morro do Fortunato ( $n=387$ citações), Santa Cruz ( $n=368$ citações) e Aldeia ( $n=644$ citações).

O fato dos entrevistados citarem mais elementos de influência vinculados ao cuidado com o corpo pode ser um reflexo das principais doenças que afetam as comunidades, que podem ser minimizadas através de mudanças nos hábitos alimentares e com uma prática regular de exercícios físicos.

A percepção de benefícios do ambiente na saúde demonstrou que elementos relacionados a serviços de regulação e provisão como a qualidade da água e do ar, seguidos de recreação e bem-estar (serviço cultural) são os mais importantes para as comunidades estudadas. Os efeitos negativos do crescimento urbano e da supressão das áreas florestais podem estar influenciando na sua maior citação. Os efeitos negativos são perceptíveis tanto próximo às comunidades - por exemplo na Santa Cruz, em que uma fábrica de arroz no centro do município gera poluição do ar para as comunidades do entorno - como também através dos meios de comunicação que divulgam impactos ambientais em outros locais do Brasil e do mundo.

Os benefícios das áreas florestais para recreação e bem-estar revelam o valor que estas áreas possuem para as comunidades quilombolas e ressaltam a importância de mantê-las dentro dos 
TABELA 3. Serviços ecossistêmicos, benefícios e desserviços obtidos dos ecossistemas identificados pelos moradores nas comunidades quilombolas do Morro do Fortunato, Santa Cruz e Aldeia.

\begin{tabular}{|c|c|c|c|}
\hline Tipo de serviço & Morro do Fortunato & Santa Cruz & Aldeia \\
\hline $\begin{array}{l}\text { Regulação: manutenção } \\
\text { do clima }\end{array}$ & $\begin{array}{l}2 \text { áreas nativas no entorno } \\
\text { dos rios }\end{array}$ & 2 quintais com árvores & $\begin{array}{l}1 \text { área nativa próximo a } \\
\text { uma nascente }\end{array}$ \\
\hline \multirow[t]{2}{*}{ Provisão: água fresca } & 4 nascentes & 4 nascentes & Lagoa de Ibiraquera \\
\hline & 3 rios & 1 rio & 5 nascentes \\
\hline $\begin{array}{l}\text { Provisão: obtenção de } \\
\text { plantas medicinais }\end{array}$ & $\begin{array}{l}1 \text { área nativa na encosta } \\
\text { do morro } \\
6 \text { quintais* }\end{array}$ & $\begin{array}{l}1 \text { área nativa na encosta de } \\
\text { morro } \\
1 \text { área de campo } \\
6 \text { quintais* }\end{array}$ & $\begin{array}{l}2 \text { locais de vegetação } \\
\text { nativa } \\
5 \text { quintais* }\end{array}$ \\
\hline $\begin{array}{l}\text { Provisão: obtenção de } \\
\text { alimentos }\end{array}$ & $\begin{array}{l}10 \text { áreas de pasto/ } \\
\text { agricultura }\end{array}$ & 3 quintais* & $\begin{array}{l}5 \text { áreas de pasto/ } \\
\text { agricultura } \\
5 \text { quintais* }\end{array}$ \\
\hline \multicolumn{4}{|l|}{ Culturais: } \\
\hline Locais históricos & $\begin{array}{l}\text { Ruínas engenho } \\
\text { Ruínas casa do Fortunato } \\
\text { Pedra do comício } \\
\text { Pedra de secar polvilho e } \\
\text { açúcar } \\
\text { Figueira }\end{array}$ & $\begin{array}{l}\text { Casa antiga } \\
\text { Nascentes }\end{array}$ & $\begin{array}{l}\text { Pesca na lagoa de } \\
\text { lbiraquera } \\
\text { Engenho de farinha } \\
\text { Caminho da Lagoa } \\
\text { Porto dos negros } \\
\text { Nascentes } \\
\text { Árvore Jambolão }\end{array}$ \\
\hline Educação & Rios & - & Engenho de farinha \\
\hline $\begin{array}{l}\text { Recreação e Ecotu- } \\
\text { rismo }\end{array}$ & Trilha de ecoturismo & Rio & $\begin{array}{l}\text { Lagoa de Ibiraquera } \\
\text { Porto dos Negros }\end{array}$ \\
\hline Espiritualidade & Associação - missas & Terreiro de Umbanda & - \\
\hline "Desserviços" & - & $\begin{array}{l}\text { Esgoto e lixo na comunida- } \\
\text { de } \\
\text { Poluição de fábrica de arroz }\end{array}$ & $\begin{array}{l}\text { Rodovia - barulho e } \\
\text { ameaça de atropela- } \\
\text { mento } \\
1 \text { rio poluído }\end{array}$ \\
\hline
\end{tabular}

* Quintais citados como mais importantes para a obtenção de plantas, embora existam outros quintais onde são cultivadas plantas medicinais e alimentícias (Ávila, 2015).

territórios destas comunidades. Para Plieninger et al. (2013) a degradação local de serviços de provisão e de regulação podem ser substituídos por meios socioeconômicos (por exemplo, a água de um poço poluído pode ser substituída por água engarrafada), mas os valores culturais de um ecossistema ou paisagem são irreparáveis.

A obtenção de recursos medicinais foi pouco citada como benefício das áreas florestais, já que a maioria das plantas medicinais citadas são cultivadas próximo às moradias. Além dos quintais próprios, os quintais de vizinhos e familiares também são importantes para obtenção das plantas, demonstrando a importância das relações sociais e de troca no uso dessas plantas. As plantas medicinais com maior porcentagem de citação são espécies exóticas e cultivadas, comuns em farmacopeias locais, o que também foi observado em outras regiões do Brasil e de países da América Latina (Bennett \& Prance, 2000).

A preferência por espécies exóticas pode ser justificada pelo fato destas estarem em ambientes mais próximos quando comparado às espécies nativas, diminuindo o custo de obtenção (Medeiros, 2013). O uso de espécies exóticas pode ter um lado positivo ao ampliar as opções de tratamento, ocupando lacunas que não são preenchidas pelas nativas (Albuquerque, 2006). Por outro lado, pode levar a homogeneização do conhecimento de plantas e o declínio na diversidade de espécies utilizadas pelas comunidades locais (Medeiros, 2013). 

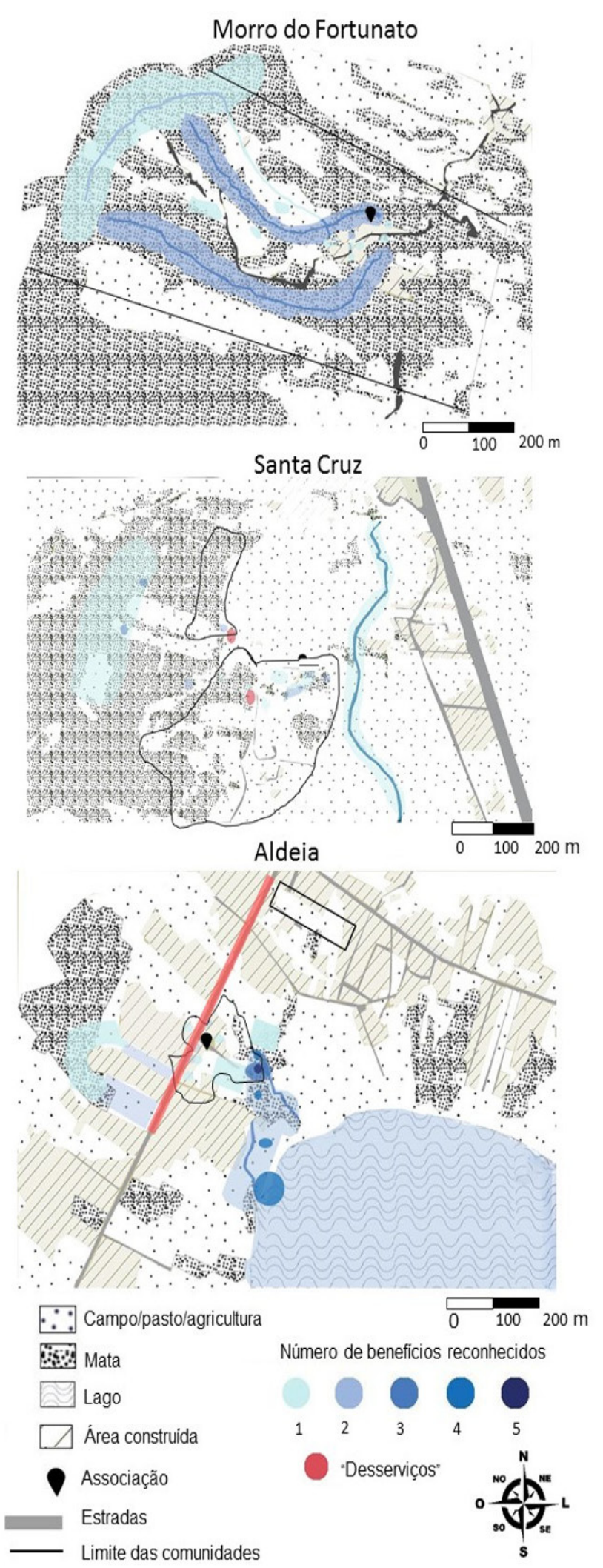

FIGURA 6. Mapeamento da percepção local sobre os ambientes que trazem benefícios e ameaças para a saúde nas comunidades quilombolas do Morro do Fortunato, Santa Cruz e Aldeia. Quanto mais escura a área, maior o número de benefícios reconhecidos.
Destaca-se também o fato da arruda $(R$. graveolens) e o alecrim ( $R$. officinalis) estarem entre as espécies mais citadas entre os quilombolas. Estas plantas são amplamente utilizadas em rituais afro-brasileiros (Camargo, 1988, Pires et al., 2009), o que demonstra a manutenção de conhecimentos relacionados à herança cultural africana.

As plantas nativas, extraídas de áreas de matas, campos e banhados, tiveram baixa porcentagem de citação indicando que atualmente estas são pouco coletadas e utilizadas, existindo uma preferência pelas plantas cultivadas e, cada vez mais, pelas compradas. A obtenção através da compra é uma alternativa para manter o uso de recursos medicinais, principalmente para as pessoas que hoje investem menos tempo ao cultivo e à extração de plantas devido ao envolvimento com trabalhos urbanos.

O mapeamento dos benefícios ambientais indicou que estes se concentram em algumas áreas prioritárias, ou o que Plieninger et al. (2013) consideraram "hotspots" em um mapeamento de serviços culturais. Morro do Fortunato e Aldeia possuem áreas com intensidade de importância maior, quando comparado com a comunidade de Santa Cruz, reflexo principalmente da quantidade de serviços culturais reconhecidos.

Além das matas, principalmente no Fortunato, os corpos d'água e seu entorno são os ambientes mais importantes para a saúde e bem-estar destas comunidades. Além de serem locais de obtenção de água potável, são também culturalmente importantes tanto por fatores históricos, de recreação, educação e turismo. Na Alemanha, Plieninger et al. (2013) também registraram que muitos serviços culturais estão localizados nos lagos, ao redor destes e nas áreas das moradias. Os desserviços registrados (esgoto, lixo, poluição do ar, rodovia) são um reflexo das ações humanas e não um reflexo das áreas naturais, o que também foi observado em comunidades da Alemanha (Plieninger et al., 2013).

A importância do mosaico de ecossistemas demonstra o papel que as práticas tradicionais desempenham na construção de um ambiente saudável para estas comunidades. Segundo Rapport (1998), paisagens saudáveis são aquelas que proporcionam uma abundância de serviços ecológicos, que se relacionam ao bem-estar humano. As comunidades do Morro do Fortunato e da Aldeia podem ser consideradas ambientes mais saudáveis no contexto deste estudo, mesmo Aldeia estando inserida em uma área urbanizada.

As áreas mais importantes para a saúde nas comunidades da Aldeia e de Santa Cruz encontramse fora do que as comunidades reconhecem como seu território atual. Desta forma, é importante 
que o processo de titulação do território destas comunidades considere estas áreas, buscando incorporá-las no território, ou criando formas de manter o acesso a elas e aos seus benefícios. Além disso, é importante considerar a governança dos comuns na perspectiva da saúde eco-cultural (Rapport \& Maffi, 2011), buscando fortalecer as organizações quilombolas no manejo das plantas medicinais e na gestão do território para a garantia dos benefícios ecossistêmicos e contribuir, desta forma, para a saúde eco-cultural.

Coutts et al. (2014) destacaram a importância de considerar a influência recíproca do ambiente natural na saúde humana e das ações humanas na saúde do ambiente, e de buscar formas de aplicar estes conceitos de interdependência nos sistemas de saúde. No caso das comunidades quilombolas isto poderia acontecer através da participação destes grupos em conselhos e fóruns de saúde, buscando garantir o acesso a serviços de saúde pública que valorizem características culturais destes grupos.

\section{CONCLUSÕES}

As comunidades quilombolas percebem diversas influências do meio ambiente em relação a saúde, sendo os elementos de cuidado com o corpo foram os mais citados, estando estes relacionados com as doenças de maior prevalência (hipertensão e diabetes). Os benefícios mais reconhecidos das áreas florestais para a saúde humana foram a qualidade da água/ar e recreação/lazer. O uso de plantas medicinais foi pouco citado como benefício das florestas, reflexo destas serem obtidas principalmente através do cultivo em quintais.

Considerando a abordagem de saúde ecocultural, o mapeamento de serviços ambientais revela áreas prioritárias para a saúde, onde foi identificada maior quantidade de benefícios ambientais. Estas áreas prioritárias estão localizadas em florestas e próximo aos corpos d'água, ressaltando a importância de conservar estes locais para construir estratégias de garantir o acesso a eles pelas comunidades.

\section{AGRADECIMENTOS}

Agradecemos as comunidades do Morro do Fortunato, Santa Cruz e Aldeia por compartilharem seus conhecimentos e tornarem esta pesquisa possível. À M.L. Mina (Movimento Negro Unificado de Santa Catarina) pela ajuda com o contato inicial com as comunidades e pelo apoio no retorno dos resultados. Ao Gaia Village, K.O. Valadares, J.Maragno, D.F.Herbst, R. Dalbem, M.C. Ribeiro, M.L. Leal, D.G. Martins, G.R. Mirizolla,
G. Pasqualetti, M.E. Beretta, G.L. Antunes, M.C.Baumann, J. Copetti and A.R. Gimenez pela ajuda durante ao trabalho de campo. A. Mello e P.C. Simionato pela ajuda na identificação botânica das plantas. C. Cáceres pelo apoio com os mapas. Ao CNPq pela bolsa de produtividade em pesquisa de N. Hanazaki (306478/2012-9) e à CAPES pela bolsa de doutorado de S. Zank e de mestrado de J.V.C.Ávila e apoio financeiro ao campo.

\section{REFERÊNCIAS}

AGYEMANG, C. et al. Cardiovascular disease, diabetes and established risk factors among populations of subSaharan African descent in Europe: a literature review. Global Health, v.5, n.7, 2009. doi:10.1186/1744-86035-7.

ALBUQUERQUE, U.P. Re-examining hypothesis concerning the use and knowledge of medicinal plants: a study in the Caatinga vegetation of NE Brazil. Journal of Ethnobiology Ethnomedicine, v.2, n.30, 2006. doi:10.1186/1746-4269-2-30.

ÁVILA, J.V.C. Contribuições Etnoecológicas para compreensão sobre territórios tradicionais de três comunidades Quilombolas de Santa Catarina. 2015. 202p. Dissertação (Mestrado - Área de concentração em Ecologia) - Departamento de Ecologia e Zoologia, Universidade Federal de Santa Catarina, Florianópolis.

ÁVILA, J.V.C. et al. The traditional knowledge of Quilombola about plants: does urbanization matter? Ethnobotany Research and Applications, v.14, p.453462, 2015.

BERNARD, H.R; RYAN, G.W. Analyzing Qualitative Data: Systematic Approaches. 1.ed.California: Sage Publications, 2010. 457p.

BENNETT, B.C.; PRANCE, G.T. Introduced plants in the indigenous pharmacopoeia of Northern South America. Economic Botany, v.54, p.90-102, 2000.

BRASIL. Manual de doenças mais importantes, por razões étnicas, na população brasileira afrodescendente. Ministério da Saúde, Secretaria de Políticas de Saúde, Brasília, 2001, 78p.

CAMARGO, M.T.L.A. Plantas Medicinais e de rituais afro-brasileiros.1.ed. São Paulo: ALMED, 1988, 97p.

COLWELL, R.K. EstimateS: statistical estimation of species richness and shared species from samples. User's Guide and application.Version 8, 2007.Disponível em: http://purl.oclc.org/estimates. Acesso em: 29 fev. 2016.

COUTTS, C. et al. The portrayal of natural environment in the evolution of the ecological public health paradigm. International Journal of Environmental Research and Public Health, v. 11, n.1, p. 1005-1019, 2014.

CUNNINGHAM, A.B. Applied Ethnobotany: People, Wild Plant use and Conservation. 1.ed. London: Earthscan, 2001.300p.

De BOEF, W.S.; THIJSSEN, M.H. Ferramentas participativas no trabalho com cultivos, variedades e sementes. Um guia para profissionais que trabalham com abordagens participativas no manejo da agrobiodiversidade, no melhoramento de cultivos 
e no desenvolvimento do setor de sementes. 1.ed. Wageningen: Wageningen International, 2007. 87p.

DIEGUES, A.C.; ARRUDA, R.S.V.; SILVA, V.C.S.; FIGOLS, F.A.B; ANDRADE, D. Biodiversidade e Comunidades Tradicionais Brasileiras. 1.ed. São Paulo, 1999. 211p.

FREITAS, D.A. et al. Saúde e comunidades Quilombolas: uma revisão da literatura. Revista CEFAC, v.13, n.5, p.937-943, 2011.

FUNDAÇÃO CULTURAL PALMARES. Comunidades quilombolas. 2014. Disponível em: <http://www. palmares.gov.br?page_id=88>. Acesso em: 16 Jun.2015

GOTELLI, N.J. Ecologia. 1.ed. Londrina: Planta, 2008. 260p.

LISTA DE ESPÉCIES DA FLORA DO BRASIL. Jardim Botânico do Rio de Janeiro. Disponível em: <http:// floradobrasil.jbrj.gov.br/>. Acesso em: 07 ago. 2015.

LORENZI, H. Plantas Daninhas do Brasil: terrestres, aquáticas, parasitas e tóxicas. 3. ed. Nova Odessa: Plantarum, 2000. 620p.

LORENZI, H.; MATOS, F.J.A. Plantas medicinais no Brasil: nativas e exóticas. 2.ed. Nova Odessa: Plantarum, 2008.544p.

MEDEIROS, P.M. Why is change feared? Exotic species in traditional pharmacopoeias. Ethnobiology and Conservation v.2, n.3, 2013. Disponível em: <http:// ethnobioconservation.com/index.php/ebc/article/ view/37/29>. Acesso em: 29 fev. 2016.

MOBOT: Missouri Botanical Garden Trópicos Search. Disponível em: http://mobot.mobot.org/W3T/Search/ vast.html). Acesso em: 7 ago. 2015.

MEA: MILLENIUM ECOSYSTEM ASSESSMENT. Ecosystems and Human Well-being: Synthesis.
Washington DC: Island Press, 2005. Disponível em: <www.millenniumassessment.org>. Acesso em: 16 jun. 2015.

PIRES, M.V. et al. Etnobotânica de terreiros de candomblé nos municípios de Ilhéus e Itabuna, Bahia, Brasil. Revista brasileira Biociências, Porto Alegre, v. 7, n. 1, p. 3-8, 2009.

PLIENINGER, T. et al. Assessing, mapping, and quantifying ecosystem services at community level. Land Use Policy, v.33, p.118-129, 2013.

RAPPORT, D.J. et al. Evaluating landscape health: integrating societal goals and biophysical process. Journal of Environmental Managment, v.53 p.115, 1998.

RAPPORT, D.J.; MAFFI, L. Eco-cultural health, global health, and sustainability. Ecological Research, v.26, p.1039-1049, 2011.

SEPPIR - Secretaria de Políticas de Promoção da Igualdade Racial. Guia de políticas públicas para comunidades quilombolas. Brasília. 2013. Disponível em: <http://www.seppir.gov.br/portalantigo/arquivos-pdf/guia-pbq>. Acesso em: $29 \mathrm{fev}$. 2015.

WHO - World Health Organization. International Statistical Classification of Diseases and Related Health Problems. Version for 2014. Disponível em: http://apps.who.int/classifications/icd10/browse/2014/ en. Acesso em: 07 ago.2015.

ZANK, S. et al. Local health practices and the knowledge of medicinal plants in a Brazilian semi-arid region: environmental benefits to human health. Journal of Ethnobiology and Ethnomedicine v.11, n.11, 2015. doi: 10.1186/1746-4269-11-11 